\title{
Confusion, Dysphasia, and Asterixis Following Metrizamide Myelography
}

MICHAEL S. SMITH and JOSE F. LAGUNA

SUMMARY: $A$ patient exhibited confusion, dysphasia, and striking asterixis 18 hours after metrizamide myelography. The symptoms lasted for $a$ day and a half. While metrizamide is a useful contrast medium, side effects are not unusual and can, on occasion, be quite severe.

RESUME: Nous décrivons un patient qui, 18 heures après une myélographie au métrizamide a développé une confusion, une dysphasie et un asterixis marqué. Ces symptomes ont duré un jour et demi. Malgré l'utilité du métrizamide, il faut noter que les effets secondaires ne sont pas rares et qu'ils peuvent, à l'occasion, être sévères.
From the Department of Neurology, University of Arizona, Tueson.

Reprint requests to Michael S. Smith, M.D., Department of Neurology, University of Arizona, 1501 N. Campbell Ave., Tucson, Arizona 85724 U.S.A.
Metrizamide is the first water soluble contrast medium to be approved for use in myelography in this country. Since its approval, it has become widely used for many reasons (Boyd and Gardner, 1977). It allows better visualization of nerve roots and its lower viscosity enables the contrast to fill the distal dural sheath, thereby defining subtle degrees of nerve root compression or impingement. As the contrast is water soluble, it need not be withdrawn at the conclusion of myelography, shortening the procedure, lessening fluoroscopy time, and producing less pain. A smaller gauge needle may be used for the initial puncture, theoretically lessening the incidence of post-lumbar puncture headache. Removal of the needle after contrast injection is routine and allows supine myelography. Finally, there is less likelihood of arachnoiditis.

Despite these advantages, significant side effects have occurred. These side effects have included transient hallucinations (Eldevik, Nakken, et al, 1978; Grainger, Kendall, et al, 1976; Sortland, Lundervold, et al, 1977), hyperacusis (Grainger, Kendall, et al, 1976), seizures (Sortland, Lundervold, et al, 1977; Lundervold and Sortland, 1977; Nickel and Salem, 1977), significant electroencephalographic (EEG) abnormalities (Sortland, Lundervold, et al, 1977; Lundervold and Sortland, 1977; Skalpe, Tabergsen, et al, 1973; Kaada, 1977; Skalpe, 1975, 1977), areflexia (Buruma and Hekster, 1977), cerebrospinal fluid (CSF) pleocytosis (Grainger, Kendall, et al, 1976; Skalpe, 1977), nausea, vomiting (Eldevik, Nakken, et al, 1978; Grainger, Kendall, et al, 1976; Nickel and Salem, 1977), and confusion (Eldevik, Nakken, et al, 1978; Sortland, Lundervold, et al, 1977; Koerner, 1979). We report a patient in whom a prolonged confusional state, dysphasic speech, includ- ing echolalia and perseveration, and striking asterixis followed metrizamide myelography.

\section{Case report}

A 43 year-old right-handed electronics technician with a past history of L5-SI disc removal for left sided $\mathrm{S} 1$ radiculopathy was admitted with a four month history of low back pain radiating to the right lower extremity and great toe. Examination was consistent with a right L5 radiculopathy. Mental status was normal.

Three days after admission, the patient underwent lumbar myelography with metrizamide. At the time of the study, he had been without food or water for five hours. The lumbar puncture was performed at the L2-3 interspace and fourteen cubic centimeters $(\mathrm{cc})$ of metrizamide, concentration $190 \mathrm{mg} / \mathrm{cc}$, was injected. All the contrast was subarachnoid. The spinal fluid had I lymphocyte/cubic millimeter, a protein of $26 \mathrm{mg}$. per cent, and a glucose of $68 \mathrm{mg}$. per cent. The myelogram demonstrated a filling defect at the L4-5 interspace on the right consistent with intervertebral disc protrusion at that level. During the procedure, the patient's head was elevated except for a brief period of time when it was lowered so as to visualize the conus medullaris.

The following morning, seventeen hours after myelography, the patient was well despite having had a transient increase in his radicular pain and some vomiting initially following the procedure. An hour later, however, he was found to be confused. At that time, his pulse was 76 , blood pressure $148 / 100$, and respiration 20. $\mathrm{He}$ was afebrile. The patient was jocular. He was oriented to name and place but did not know month or year. When asked who the examiner was, the patient continually repeated the question and showed marked perseveration with other lines of questioning as well. He was unable to name the president or to repeat a series of digits. He did, however, remember the examiner after a two minute hiatus. Speech was clear, occasionally halting, with difficulty saying "no ifs, ands, or buts." The patient could follow simple one step 
commands, such as to raise one hand or to close his eyes, but was unable to follow two step directional commands, such as to place his left hand over his right eye. $\mathrm{He}$ was able to name objects correctly, although with increasing speed perseveration occurred. Drawings were characterized by perseveration, and the patient's handwriting was markedly dysgraphic.

Examination of cranial nerves, motor, coordination, and sensation were unchanged from admission. There was pronounced asterixis demonstrable in both the hands and the feet. The left plantar response was flexor, the right extensor. Straight leg raising no longer elicited pain, and the patient's previously antalgic gait had disappeared.

Laboratory results included a hematocrit of 44 and a white count of 12,300. Electrolytes, BUN, creatinine, glucose, and prothrombin time were all normal. Twentyfive grams of intravenous glucose produced no change. An EKG was normal, and repeat CSF analysis was normal.

The patient was observed overnight in the intensive care unit. Eight hours after onset of the confusional state he was unchanged. The following morning, twenty hours after onset, he was better, being oriented to person, place, and time, but with some expressive aphasia and perseveration still present. The asterixis had disappeared. An EEG at this time showed generalized slowing with intermittent frontal bursts of high voltage $1-2 \mathrm{~Hz}$ activity and occasional right anterior temporal sharp waves. By that evening, thirty-two hours after the onset of the confusional state, the patient's mental status was normal. He then related that his head had been horizontal for about twenty minutes immediately after returning from the radiology department. He had tried to inform the nursing staff of the need to elevate his head but, in his words, "I was told that everyone knows after a myelogram you have to lay flat." He subsequently declined surgery.

\section{DISCUSSION}

This is at least the second reported case of a prolonged confusional state following metrizamide. Sortland, et al (1977) reported a case where a man first became confused an hour after myelography and then had two seizures a few hours later. No mention was made of axterixis. Two and a half days later, he was found wandering on another floor of the hospital. While initially calm, he became belligerent when he was returned to his room and required "high doses" of chlorproma- zine for sedation. His EEG likewise showed bifrontal slowing with a right sided preponderance. That case, however, followed cervical myelography with cervical spine flexion, a factor that could have increased the likelihood of complications.

Including heacache, nausea, and vomiting, the side effects of metrizamide may be considerable. Eldevik et al (1978) reported a total incidence of $64 \%$, increased among patients dehydrated prior to myelography. Anxiety, confusion, and hallucinations occurred in thirteen patients and lasted a few hours, but no further details were given. Grainger (1976) reported headaches following myelography in $43 \%$ but nausea and vomiting in only $12 \%$. Hyperacusis and transient hallucinations occurred but were not considered major problems. Instam and Sellden (1976) noted headaches in $34 \%$ of their patients and side effects in 58\%. They concluded that previous injury to the brain increased the likelihood of side effects referable to that particular area. Hindmarsh (1975) found that a transient increase in back and leg pain following metrizamide myelography was common. Clonic spasms of the legs were noted as well, but no true spinal myoclonus occurred.

EEG abnormalities, CSF abnormalities, and seizures after metrizamide myelography have been of some concern. Grainger (1976) reported $16 \%$ of patients after metrizamide myelography had EEG abnormalities. In Instam and Sellden's series (1976), EEG abnormalities occurred in $8 \%$ with some bursts seen but no definite paroxysmal activity. Skalpe (1975) found 13 of 79 patients with transitory EEG abnormalities following use of metrizamide and 21 of 29 patients with CSF pleocytosis. Two years later, he noted a $32 \%$ incidence of EEG abnormalities with some spike-wave activity seen (Skalpe, 1977). Kaada (1977) performed electroencephalography before and after use of metrizamide. There was a $10 \%$ incidence of EEG abnormalities in the pre-study population and $16 \%$ in the post-study population. He felt that many of the post-metrizamide EEGs simply accentuated the pre-existing abnormality. Lundervold and Sortland (1977) described two abnormal EEG patterns: the first was transitory slow waves occurring no sooner than 24 hours following myelography. The second pattern was evident as early as four hours after myelography and consisted of spikes, sharp waves, atypical spike and wave patterns, and intermittent rhythmic frontal delta activity. Three percent of their patients had seizures, compared with $0.4 \%$ in Nickel's series (1977) and none in Grainger's (1976). Seizures are felt to be due to the direct toxic effect of metrizamide upon the cerebral cortex. Indeed, in dogs, metrizamide has been shown by autoradiography to concentrate along a gradient in the superficial layers of the cortex (Drayer and Rosenbaum, 1977).

There is little question that metrizamide is a useful advance in myelography. The above case and discussion should illustrate, however, that pre-myelography central nervous system disease, the dose and location of metrizamide, and post-myelography care are crucial parameters that must be considered in the selection of metrizamide for the individual patient. Ahlgren's statement (1975): "Amipaque is so innocuous that it can be used in all regions of the spinal canal ..." would appear at this time to be excessively optimistic.

\section{REFERENCES}

AHLGREN, P. (1975). Amipaque myelography. The side effects compared with dimer $X$. Neuroradiology, 9, 197-202.

BOYD, W.R., GARDINER, G.A. (1977) Metrizamide myelography. Am. J. Radiology, 129, 481-84.

BURUMA, O.J.S., HEKSTER, R.E.M. (1977). Transient areflexia following thoracolumbar myelography with metrizamide. Acta Radiologica, Supp. 355, 371-72.

DRAYER, B.P., ROSENBAUM, A.E.: Metrizamide brain penetrance. Acta. Radiologica, Supp. 355, 280-93.

ELDEVIK, O.P., NAKKEN, K,O., HAUGHTON, V.M. (1978). The effect of dehydration on the side effects of metrizamide myelography. Radiology, 129, 715-16.

GRAINGER, R.G., KENDALL, B.E., WYLIE, I.G. (1976). Lumbar myelography with metrizamide, a new non-ionic contrast medium. Brit. J. Rad. 49, 996-1003.

HINDMARSH, T. (1975). Lumbar myelography with meglumine iocarmate and metrizamide. Acta Radiologica Diagnosis, Supp. 16, 209 . 22.

KOERNER, M. (1979). Implication of metrizamide myelography. Arch. Neurol. 36, 859. 


\section{LE JOURNAL CANADIEN DES SCIENCES NEUROLOGIQUES}

INSTAM, L., SELLDEN, U. (1976). Adverse effect of lumbar myelography with amipaque and dimer-x. Acta Radiologica, 17, 145-59.

KAADA, B. (1977). Transient EEG abnormalities following lumbar myelography with metrizamide. Acta Radiologica, Supp. 355. 380-86.

LUNDER VOLD. A., SORTLAND, O. (1977). EEG disturbances following myelography cisternography, and ventriculography with metrizamide. Acta Radiologica, Supp. 355 , 379-89.
NICKEL, A.R., SALEM, J.J. (1977). Clinical experiences in North America with metrizamide. Acta Radiologica, Supp. 355, 409-16.

SKALPE, 1.O. (1975). Lumbar radiculography with metrizamide. Radiology, 115, 91-95.

SKALPE, 1.O. (1977). Adverse effects of watersoluble contrast media in myelography. cisternography, and ventriculography. Acta. Radiologica, Supp. 355, 359-70.
SKALPE, I.O., TORBERGSEN, T., AMUNDSEN. P.. PRESTHUS, J. (1973). Lumbar myelography with metrizamide. Acta Radiologica, Supp. 355, 367-79.

SORTLAND, O., LUNDERVOLD, A., NESBAKKEN, R. (1977). Mental confusion and epileptic seizures following cervical myelography with metrizamide. Acta Radiologica, Supp. 355, 403-405. 